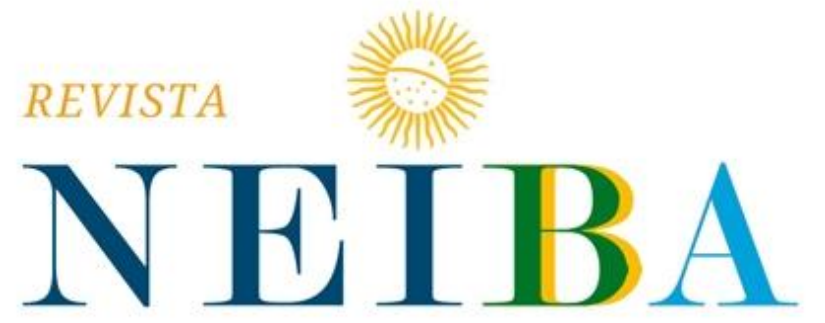

CADERNOS ARGENTINA-BRASIL
Volume 9,2020 , p. 01-28

DOI: 10.12957/neiba.2020.50599|e50599 I ISSN: 2317-3459

\title{
POLÍTICA EXTERNA, DEMOCRACIA E DIREITOS HUMANOS: UMA ANÁLISE INICIAL DO RECONHECIMENTO BRASILEIRO DA JURISDIÇÃO DA CORTE INTERAMERICANA DE DIREITOS HUMANOS
}

FOREIGN POLICY, DEMOCRACY AND HUMAN RIGHTS: AN INITIAL ANALYSIS OF THE BRAZILIAN RECOGNITION OF THE INTER-AMERICAN COURT OF HUMAN RIGHTS JURISDICTION

\section{Guilherme Antunes Ramos ${ }^{1}$}

${ }^{1}$ Universidade do Estado do Rio de Janeiro (UERJ), Rio de Janeiro, RJ, Brasil. E-mail: guilhermeramos.ir@gmail.com ORCID: https://orcid.org/0000-0002-8224-9074

Recebido em: 01/01/2020 | Aceito em: 27/04/2020. 


\section{RESUMO}

O trabalho se propõe a analisar, em linhas gerais, a decisão de submeter o Brasil à jurisdição da Corte Interamericana de Direitos Humanos, anunciada em dezembro de 1998. Trata-se de um trabalho de natureza exploratória que objetiva apontar múltiplas possibilidades no que tange aos interesses, objetivos e preferências que nortearam a decisão brasileira, bem como à própria estruturação do processo decisório, manifesta a partir da indicação dos atores sociais que dele fizeram parte, e de sua possível abertura ou alheamento à participação da sociedade civil. A ideia central é compreender melhor a inserção internacional do Brasil no sistema internacional de proteção aos direitos humanos tendo por base a análise de uma decisão considerada como revestida de extrema significância. Ademais, pretende-se investigar a importância do tópico dos direitos humanos na agenda internacional brasileira.

Palavras-chave: Política externa brasileira; direitos humanos; Corte Interamericana de Direitos Humanos.

\section{ABSTRACT}

This paper analyses, in general lines, the decision to submit Brazil to the jurisdiction of the Inter-American Court of Human Rights, announced in Dezember, 1998. This is an exploratory study whose objectives revolve around signaling multiple possibilities regarding the interests, objectives and preferences that inspire the brazilian decision, as well as the own structuring of the decision-making process, expressed by the identification of the social actors that had a participation in it, and its possible openness to civil society participation. The main idea is to have a better undestanding of brazilian international insertion in the human rights international protective system based on the analysis of a decision considered to be extremely relevant. Moreover, it is intended to investigate the importance of the human rights topic in the brazilian international agenda.

Keywords: Brazilian Foreign Policy; human rights; Inter-American Court of Human Rights. 


\section{INTRODUÇÃO}

A temática dos direitos humanos adquiriu crescente notoriedade ao longo do século XX. A assunção de reiterados compromissos destinados a salvaguardar o acesso a esses direitos, tanto nos âmbitos nacionais quanto na esfera internacional, manifestava uma centralidade então inédita da condição humana. A parte mais bela e importante de toda a História, segundo Fábio Comparato, começava a ser contada (2015, p. 10). De forma totalmente singular, os Estados-Nação começavam a se mobilizar a fim de proteger direitos considerados como fundamentais a uma existência digna. Dessa mobilização resultou um sofisticado arranjo internacional destinado a conceber, proteger e consagrar os direitos humanos, os quais incluem desde tratados internacionais como pactos e convenções até instrumentos jurídicos de natureza contenciosa, como tribunais internacionais. O direito internacional, dessa forma, começava a se humanizar à medida que a condição humana passava a adquirir proeminência em detrimento de um estatocentrismo irrestrito que até então dominava os assuntos internacionais (Ramos, 2018, p. 93).

O presente trabalho dá início à análise de uma notória decisão dos policy makers brasileiros inserida nesse macroprocesso de internacionalização dos direitos humanos e humanização do direito internacional, qual seja, o reconhecimento, por parte do Brasil, da jurisdição da Corte Interamericana de Direitos Humanos, órgão contencioso inserido nos marcos do Sistema Interamericano de Direitos Humanos (SIDH). Considera-se ser dito sistema uma iniciativa hemisférica paradigmática destinada a proteger os direitos humanos no continente americano; outrossim, a constituição específica de uma corte internacional no âmbito desse sistema representaria também um esforço inédito de judicialização supranacional dos direitos humanos na região, sendo uma iniciativa ilustrativa da crescente centralidade do indivíduo em detrimento do Estado na conjuntura internacional contemporânea. A submissão a uma corte internacional de direitos humanos, para além de se configurar em um aperfeiçoado mecanismo destinado à proteção individual e coletiva dos direitos humanos, evidenciaria ainda uma transfiguração do princípio de soberania estatal, princípio basilar das relações internacionais tradicionalmente mobilizado pelos operadores da política externa 
brasileira como um dos vetores da inserção internacional do país. A sujeição do Brasil à jurisdição da Corte Interamericana de Direitos Humanos refletiria, portanto, uma reformulação da soberania por parte dos policy makers, a qual passaria a ser ressignificada em face de novas contingências, mormente o fortalecimento da agenda dos direitos humanos e da universalidade que teoricamente os orienta e norteia sua aplicabilidade.

Desponta como um objetivo principal analisar, em linhas gerais, a decisão brasileira de finalmente aderir à Corte Interamericana de Direitos Humanos após um prolongado hiato de hesitação dos decisores em matéria de política externa. Em linhas gerais, buscar-se-á responder à seguinte pergunta? Por que o Brasil resolveu finalmente se submeter à jurisdição da Corte Interamericana de Direitos Humanos? Trata-se de um estudo de natureza exploratória, na medida em que interpela uma série de hipóteses que ajudariam a compreender a decisão dos policy-makers brasileiros, bem como a apreensão dos objetivos que perseguiam.

Prenuncia-se de antemão que o trabalho se inspira em produções e reflexões inseridas nos marcos da Análise de Política Externa (APE). Considera-se ser a APE um sub-campo de pesquisa na área de Relações Internacionais que se ocupa da abertura da "caixa preta" do processo decisório em política externa (Hudon; Vore, 1995, p. 211). Em outras palavras, a APE traduz um renovado interesse nas instâncias decisórias e nas variáveis domésticas quando da avaliação da gestação de políticas externas. Os estudos inseridos nesses marcos rompem com o pretenso monolitismo do Estado e inauguram novas possibilidades de estudos em política externa, com foco na agência humana e na circulação de ideias, interesses, preferências e papéis. A APE, vis-à-vis as principais macroteorias de Relações Internacionais, inverteria meios e fins: a avaliação do processo que antecedeu a tomada de decisão passa a ser tão importante quanto a compreensão dos resultados (outcomes) da política externa. Assim sendo, variáveis anteriormente neutralizadas são valorizadas a partir de uma nova proposta de estudos sobre política externa. A negociação política e as circunstâncias em que decisões de política externa foram tomadas passam, com efeito, a se tornar objetos de estudo. A APE possibilita, portanto, estudos sobre biografias, burocracias governamentais, 
composição de papéis internacionais (role concept theory), transições de regimes políticos, interveniência de atores não-estatais no processo decisório, como ONGs, think tanks e a mídia, dentre outros. Em termos mais amplos, a APE buscará conjugar a análise de variáveis sistêmicas e domésticas quando da formulação de política externa, abrindo infinitas possibilidades de abordagens no campo teórico e criando inúmeras ferramentas a serem replicadas para a análise de casos empíricos.

Ademais, destaca-se que o trabalho adota a conceituação de política externa como política pública, em consonância com entendimento partilhado em Milani; Pinheiro, 2013. Dentre as principais repercussões focalizadas pelos autores, decorrentes dessa conceituação, destaca-se a efemeridade e a transitoriedade da política externa (2013, p. 25). Esse posicionamento revela que, longe de ser estanque e manter uma linha de continuidade perene ao longo do tempo, a política externa reflete processos negociacionais altamente complexos, envolvendo um amplo debate público que mobiliza vozes dissonantes e distintos projetos de inserção internacional. A política externa como política pública é, desde logo, uma política efêmera, contingente, transitória: as razões para a mudança passam a ser alvo de investigação. E, para além disso, precisa ser objeto de um diálogo plural e aberto com a sociedade civil.

Partindo desse entendimento de que a política externa muda, e que diferentes variáveis podem justificar ditas mudanças, focalizar-se-á aqui uma importante variável doméstica que poderia ajudar a explicar a inflexão na política externa acerca do episódio em questão, a saber, a mudança de regime. Considera-se que a transição democrática foi imprescindível para que o Brasil pudesse por fim ratificar o Pacto San José da Costa Rica em 1992 e posteriormente aceitar a jurisdição da Corte Interamericana de Direitos Humanos em 1998. A consolidação da democracia após o interstício ditatorial teria sido determinante, nesse sentido, para a assunção de compromissos internacionais em matéria de direitos humanos, por autorizar canais de pressão advindos da própria sociedade civil e multiplicar as possibilidades de influência dentro do próprio círculo governamental. Mais particularmente, a ascensão de um novo grupo político que partilhava do entendimento de que era de interesse do Brasil aderir aos principais regimes e normativas internacionais também seria uma explicação 
possível para a tomada da decisão em estudo. Nesse sentido, a busca pela autonomia pela via da participação (Fonseca, 1998) seria, desde o ponto de vista da política doméstica, um elemento que teria corroborado para a decisão brasileira em sujeitar o país ao arbítrio de um tribunal internacional. Destaca-se, contudo, que a busca por explicações domésticas não esgotará possibilidades advindas de variáveis sistêmicas. Contrariamente a essa percepção, elementos externos também serão destacados. Hipotetiza-se que um elemento conjuntural que teria corroborado para a decisão brasileira seria a crescente normatização da agenda dos direitos humanos, a qual se fortaleceu e se irradiou sobretudo após o fim da Guerra Fria. A força revigorada dos direitos humanos, que mobilizavam grupos de pressões internos e externos, aliado às mudanças operacionalizadas no campo do regime e da política interna do Brasil, comporia uma explicação possível à decisão brasileira. A síntese de elementos domésticos/sistêmicos como explicação para a tomada de uma decisão em política externa se constitui na principal hipótese a ser testada ao longo da pesquisa iniciada no presente trabalho.

Em termos metodológicos, o artigo procederá a uma análise de conteúdo manifesto tanto em fontes primárias quanto secundárias. As fontes primárias se comporão em notícias extraídas dos periódicos O Globo e Jornal do Brasil, dois dos principais jornais de circulação diária ao longo da década de 1990, disponibilizadas em acervo digital. Procedeu-se a uma busca por notícias a partir da utilização da expressãochave "Corte Interamericana de Direitos Humanos", adotando o recorte temporal de 1990 a 1999. A consulta a essas fontes primárias justifica-se na medida em que o recurso a elas possibilita um olhar geral sobre o processo decisório em política externa naquele momento. Por intermédio das notícias, buscar-se-á investigar se a decisão brasileira de aderir à Corte Interamericana de Direitos Humanos foi insular ou se mobilizou um debate público. As publicações midiáticas serviriam a esse fim, diante da carência de fontes oficiais de acervos diplomáticos, as quais não puderam ainda ser consultadas em razão de constrangimentos temporais. Já as fontes secundárias se constituirão basicamente em uma bibliografia especializada de apoio que, em conjunto com as fontes primárias, subsidiarão as análises iniciais da decisão brasileira. 
O artigo se subdividirá em duas grandes seções: a primeira, de caráter teórico, recapitulará algumas das principais contribuições da Análise de Política Externa (APE); a segunda apresentará, em síntese, o Sistema Interamericano de Direitos Humanos (SIDH), apontando particularmente para a importância da Corte Interamericana de Direitos Humanos, além de propor uma análise inicial da decisão brasileira em se submeter à jurisdição desse órgão, através da tentativa de recomposição do processo decisório a partir da análise das notícias destacadas. Ao fim, as inferências preliminares serão destacadas em uma seção conclusiva.

\section{A ANÁLISE DE POLÍTICA EXTERNA (APE): A POLÍTICA EXTERNA COMO OBJETO DE ESTUDO E SUAS MÚLTIPLAS POSSIBILIDADES}

A Análise de Política Externa é definida em Alden; Aran, 2012 como o estudo da conduta e da prática de relações entre diferentes atores, primariamente os Estados, no sistema internacional (2012, p. 1). A autora Valerie Hudson, por sua vez, concebe a Análise de Política Externa como um "sub-campo de Relações Internacionais que objetiva explicar a política externa ou, alternativamente, o comportamento da política externa, com referência ao arcabouço teórico dos humanos tomadores de decisão, agindo em grupos ou individualmente" (2012, p. 14, tradução minha). Ainda segundo Hudson, a APE teria um caráter distintivo se comparada a outras abordagens de política externa por se propor, dentre outros, a olhar para além do nível de análise do Estado, buscando por fontes de influência sub-nacionais, além de firmar um compromisso de perseguir explicações multi-níveis, que integrem variáveis e fenômenos manifestos em diferentes níveis de análise. A autora, por fim, destaca que a APE teria como traço característico a consideração de que o processo decisório de política externa é tão importante quanto os resultados políticos das decisões tomadas (2012, p. 14).

Das considerações aportadas pelos autores anteriormente citados, retém-se que a Análise de Política Externa integra um conjunto de estudos que dedicam uma atenção diferenciada ao processo decisório em política externa. Em termos mais amplos, ditos estudos buscam descortinar o processo de negociação política que circunscreve a tomada de decisões em matéria de política externa, investigando ainda as possibilidades de interferência exógena nesse processo, tanto de atores externos stricto 
sensu quanto de atores internos, incluindo aqueles que não integram diretamente o círculo decisório tomador de decisões. A APE se insurge contra uma tendência de desconsideração de variáveis domésticas quando da avaliação da política externa, além de se contrapor à ideia de que a política externa se orientaria segundo um ideal de interesse nacional permanente, a se perpetuar no tempo a despeito de quaisquer contingências. Alternativamente, a APE considerará que a política externa se apresenta como um processo de negociação dinâmico e adstrito por forças externas e internas, e que os resultados que produz devem ser pensados à luz da estruturação do processo decisório. Em resumo, a APE pressupõe modelos multicausais de determinantes de política externa, rechaçando percepções que tendem a generalizar as decisões de política externa segundo condicionantes partilhados por todos os Estados, seja a conceituação de um interesse nacional perene, manifesto em termos de poder material (como pressuposto pelos realistas clássicos), seja pela concepção do Estado como ator racional que persegue ações externas unicamente a partir de um cálculo que pondera custos e benefícios (premissa partilhada pelos teóricos da Escolha Racional).

Retém-se que a APE apresenta como um importante legado a multiplicação de variáveis a serem consideradas dentro de um estudo que se propõe a explicar fenômenos de política externa. Boa parte dos estudos que se inserem nos marcos da APE originou-se em reação à desconsideração sistemática de parte significativa dessas variáveis pelos paradigmas e macroteorias dominantes na área de Relações Internacionais. A APE inaugura, desde logo, uma nova abordagem, e o poder explicativo gerado por trabalhos produzidos em seu seio inclusive corroborará um movimento de revisão da importância de variáveis domésticas quando da avaliação de políticas externas. Mesmo o realismo, em sua variante neoclássica, dedicará uma atenção mais direcionada ao processo decisório que antecede a formulação de políticas externas, mobilizando em sua análise variáveis e processos domésticos. Admitem os autores realistas neoclássicos a necessidade de se adentrar o nível de análise doméstico, objetivando abrir a "caixa preta" do processo decisório em política externa: "Because neoclassical realism requires researchers to answer questions about the reasons why particular policies were selected, it requires them to get inside the black box of the 
state to be able to answer these questions with reasonable certainty" (Ripsman; Taliaferro; Lobell, 2016, p. 132). Assim sendo, infere-se que a consideração do processo decisório em política externa focalizada pela APE repercutiu sobre as macroteorias de Relações Internacionais, disseminando um interesse renovado em instâncias e dinâmicas políticas e sociais internas.

O advento da APE promove, portanto, a multiplicação de variáveis a serem consideradas quando da avaliação de políticas e resultados externos. Ideias, ideologias, influências de atores não-estatais, personalidades e mesmo a biografia de indivíduos tomadores de decisão passarão, com efeito, a se tornar objeto de investigação. As mudanças de regime político e seus possíveis efeitos sobre a política externa serão igualmente focalizados pela APE. Christopher Hill, por exemplo, adiciona a mudança de regime, além das classes sociais, aos "4Ps" tradicionalmente focalizados por estudiosos da política externa como possíveis fontes de mudança (Parlamento, opinião pública, grupos de pressão e imprensa - todos iniciados por " $\mathrm{P}$ " no original em inglês). Conforme resume o autor: "the nature of any political system does help to determinate the direction of a foreign policy" (2003, p. 239). O argumento desenvolvido em Lima, 2000, não só corrobora esse ponto, como também descontrói a pretensa fronteira entre política externa e democracia, subvertendo o argumento segundo o qual a política externa deveria se manter apartada do debate democrático, sendo formulada e implementada apenas por autoridades dotadas da expertise necessária para tal empreendimento. A autora critica a despolitização da política externa brasileira, no sentido de insulamento em uma burocracia especializada - o Ministério das Relações Exteriores. Para a autora, a consolidação da democracia no Brasil, aliada ao fenômeno em curso da Globalização, tornariam a política externa brasileira cada vez menos especializada e mais debatida publicamente. Assim sendo, haveria uma tendência cada vez mais acentuada de se trazer temas de política externa para as arenas de debate público, tendência essa que dependeria sobremaneira da natureza democrática do regime político instalado no país.

A menção a priori ao estudo sobre as mudanças de regime e, mais especificamente, sobre a relação entre democracia e política externa, é imprescindível para os propósitos 
do presente trabalho, sobretudo porque se acredita que a política externa de fato precisa ser debatida publicamente. Nesse sentido, partilha-se da opinião de Paulo Velasco, para quem:

É imperativo reconhecer que além de uma política de Estado em favor da proteção da soberania e da integridade territorial e da projeção de poder no exterior, a política externa também é o resultado das disputas de poder existentes no âmbito interno, traduzindo as preferências e prioridades daqueles que conseguiram se afirmar e prevalecer. Reconhecendo-se que a separação radical entre o doméstico e o internacional é uma arbitrariedade a ser evitada e, hoje em dia, largamente questionada no plano teórico, cumpre afirmar, portanto, a política externa como uma política pública. (Velasco, 2019, p. 498)

A afirmação da política externa como política pública perpassa necessariamente, a nosso ver, por sua politização, por sua abertura à participação e interveniência de múltiplos atores sociais e por sua incorporação ao debate democrático. Em temas como direitos humanos é ainda mais importante que haja um pleno alinhamento entre os compromissos internacionalmente assumidos pelo Brasil através de sua política externa e as percepções socialmente difundidas dentre sua própria sociedade civil. Avalia-se que um possível déficit democrático da política externa brasileira, que teria resultado na adesão a regimes internacionais de direitos humanos sem plena sensibilização da sociedade civil, teria resultado na construção de dois "Brasis": um Brasil externo, que endossa e participa das principais tratativas internacionais de direitos humanos; e um Brasil interno, que questiona os direitos humanos e sua universalidade e enxerga nessa agenda não a consagração de seus interesses, mas um projeto muitas vezes danoso à própria sociedade. Nesse sentido, o comportamento externo estaria dissociado de dinâmicas domésticas.

Julga-se que, tivesse a política externa brasileira efetivamente se politizado, e se cada adesão do Brasil a um tratado protetivo de direitos humanos fosse precedida de um debate público, ao invés de ser decidida em um círculo fechado por especialistas que pretensamente gozavam da prerrogativa inequívoca de deliberar sobre tais temas, provavelmente haveria uma outra percepção da sociedade brasileira sobre os direitos humanos. E os compromissos internacionalmente assumidos pelo Brasil possivelmente seriam melhor aplicados internamente. Conforme pontua o autor Amartya Sen, a democracia cumpre um papel construtivo na conceituação das necessidades de uma 
população (2010, p. 195). A politização da politica externa, assim sendo, poderia ter contribuído para a construção de uma pedagogia dos direitos humanos, no sentido de sensibilizar a sociedade brasileira acerca da importância dos direitos humanos e de sua proteção. Hipotetiza-se que o possível insulamento da política externa tornou os direitos humanos no Brasil um projeto distante da sociedade brasileira, que não o compreende e tampouco vislumbra nele o tratamento de suas necessidades. A verificação dessa hipótese é iniciada no presente trabalho. E também por isso optou-se por trabalhar com notícias de periódicos, na medida em que o número e a frequência de notícias sobre a adesão do Brasil à Corte Interamericana de Direitos Humanos pode ser um indicador da politização ou não dessa decisão em matéria de política externa.

Desta seção introdutória, retém-se que as produções inseridas no âmbito da APE estimulam uma atenção destacada ao processo decisório, além de diversificarem sobremaneira as variáveis a serem potencialmente mobilizadas quando da avaliação de uma decisão tomada em matéria de política externa. Tendo por inspiração as reflexões produzidas no âmbito desse sub-campo de pesquisa em Relações Internacionais, serão suscitadas a seguir inúmeras questões referentes à aceitação do Brasil da jurisdição da Corte Interamericana de Direitos Humanos, de modo a se problematizar essa decisão à luz da estruturação da política externa brasileira.

\section{A DECISÃO DO BRASIL DE ADERIR À CORTE INTERAMERICANA DE DIREITOS} HUMANOS: APRECIAÇÕES INICIAIS

O Sistema Interamericano de Direitos Humanos (SIDH) pode ser compreendido como uma variante hemisférica do processo generalizado de internacionalização dos direitos humanos fortalecido no pós Segunda Guerra Mundial. Com efeito, a Declaração Universal de Direitos Humanos e os pactos e compromissos globais que se seguiram a ela, para além de sedimentarem uma nova ética pretensamente universal acerca da importância dos direitos humanos, também inspiraram a assunção de compromissos locais destinados a consagrar os referidos direitos em circunscrições territoriais específicas. Surgem, na esteira desse processo, os sistemas regionais de proteção dos direitos humanos, que podem ser definidos como "organismos internacionais (dos diversos continentes) como o sistema universal, só que aqueles atuam regionalmente" 
(Miranda; Cunha, 2010, p. 33).

O SIDH se inicia através de uma iniciativa conjunta dos países americanos reunidos na Organização dos Estados Americanos (OEA). Como uma primeira grande iniciativa capitaneada pela OEA para endereçar a temática dos direitos humanos na região, destaca-se o Pacto San José da Costa Rica, também conhecido como Convenção Americana de Direitos Humanos. A Convenção viabiliza a criação da Corte Interamericana de Direitos Humanos, que entra em vigor em 18 de julho de 1978 (Guerra e Silva, 2018, p. 5), além de também tipificar as atribuições da Comissão Interamericana de Direitos Humanos, órgão fundado em 1959. Conjuntamente, a Comissão e a Corte se apresentam como as principais instâncias direcionadas à salvaguarda dos direitos humanos no hemisfério americano.

A Corte Interamericana de Direitos Humanos exerce duas funções: consultiva e contenciosa, sendo a última a principal delas. Acerca das funções da Corte, assinala-se que:

\begin{abstract}
La función consultiva se refiere a la facultad que los Estados miembros de la OEA tienen de consultar a la Corte respecto a la interpretación de la Convención o de otros tratados relaciones a la protección de los derechos humanos, así como sobre la compatibilidad de leyes internas y dichos instrumentos referidos.

Por otra parte, la función contenciosa surge cuando la Comisión IDH, al ejercer el juicio de admisibilidad, decide someter el caso a la Corte IDH. Primero, el individuo, representado o no por una organización no gubernamental, presenta ante la Comisión petición que contengan denuncia o quejas de violación de la Convención por un Estado parte. Así, la Comisión ejercerá el juicio de admisibilidad, averiguando si el Estado parte violó los derechos humanos contenidos en la Declaración Americana, en la Convención y otros Tratados internacionales de derechos humanos. Una vez que considere que el Estado no tomó las medidas necesarias para reparar la violación, la Comisión someterá el caso a la Corte para que esta ejerza su función jurisdiccional. (Guerra e Silva, 2018, p.16).
\end{abstract}

Verifica-se, desde logo, que a função contenciosa da Corte Interamericana de Direitos Humanos atribui a este órgão importância fundamental em se tratando do acesso a medidas protetivas de direitos humanos na região. Ao permitir que indivíduos, esgotadas as instâncias internas de seus respectivos Estados, possam acessar um tribunal internacional para reivindicar a consagração de direitos que lhes foram negados, a Corte autoriza a gestação de uma personalidade jurídica internacional para os indivíduos na região. Assim, corrobora para o processo anteriormente citado de 
humanização do direito internacional, à medida que consagra uma proteção humanitária que se sobrepõe ao próprio domínio do Estado; ademais, é um sintoma da ressignificação do princípio de soberania estatal, posto que destitui dos Estados a exclusividade de jurisdicionar sobre a proteção de suas próprias populações.

Ressalta-se, contudo, que, diferentemente da Comissão Interamericana de Direitos Humanos, a Corte Interamericana "é uma instituição judicial autônoma, não sendo órgão da OEA, mas sim da própria Convenção Americana" (Miranda, Cunha, 2010, p. 43). Disso resulta que, para que os nacionais de um determinado Estado tenham acesso às medidas de proteção deste tribunal, faz-se necessário que seu Estado de origem tenha formulado uma declaração unilateral de reconhecimento de sua jurisdição. Não basta a assinatura/ratificação da Convenção Interamericana de Direitos Humanos, uma vez que a jurisdição da Corte é apresentada em uma cláusula facultativa (idem, p. 44). O Brasil somente reconheceu a jurisdição da Corte em 1998, 20 anos após a referida instância iniciar as suas atividades.

Torna-se objeto de investigação do presente estudo analisar, em linhas gerais, a decisão brasileira de finalmente reconhecer a jurisdição da Corte. Trata-se, com efeito, de uma decisão em matéria de política externa extremamente significativa para o país e para a sociedade brasileira, haja visto que promove um novo mecanismo supranacional de provisão de direitos, além de subverter a preservação de uma soberania tradicional que recorrentemente tem orientado os policy makers brasileiros em suas decisões. É, nesse sentido, um importante passo dentro do espectro mais amplo de construção de arranjos internacionais protetivos de direitos humanos. Como uma estratégia de abordagem inicial do processo de tomada de decisões e da conjuntura que norteou dita decisão, serão primeiramente destacadas as repercussões midiáticas da decisão brasileira, através dos periódicos O Globo e Jornal do Brasil. Buscar-se-á adquirir um panorama geral sobre a decisão através da Imprensa, além de analisar, via frequência das notícias e da análise de conteúdo de alguns casos ilustrativos, se a referida decisão teve alguma ressonância sobre a sociedade civil, mobilizando um debate democrático sintomático de uma concepção de política externa como política pública.

A consulta ao acervo do jornal "O Globo" evidencia que foram de fato escassas as 
publicações que tratavam da Corte Interamericana de Direitos Humanos e do reconhecimento de sua jurisdição pelo Brasil. Destaca-se como uma primeira publicação de relevância a nota editorial intitulada "Má desculpa", publicada em edição do dia 28 de outubro de 1995. No referido editorial, aludia-se explicitamente à recusa do país em se submeter à jurisdição da Corte e defendia-se posição contrária, mobilizando argumentos dignos de menção:

O Brasil não ficará em situação cômoda se não se submeter a julgamentos da Corte Interamericana de Direitos Humanos. Principalmente se se escudar atrás do cansado argumento da interferência indébita em assuntos internos. A divisão de Direitos Humanos do Itamaraty alega que o Brasil se exporia a vexames, por ter uma Justiça muito lenta e por não poder o Governo federal intrometer-se em assuntos de competência dos estados. É verdade mas não é desculpa.

Impõe-se encontrar argumentos jurídicos que sirvam de alternativa à recusa. E respaldá-los com ações concretas no sentido de ajudar a Justiça a ser mais ágil e as autoridades estaduais da área da segurança mais zelosas. (O Globo, 1995).

Destaca-se, primeiramente, que o jornal menciona o argumento soberanista. A submissão do país a uma corte internacional representaria, sob a lógica desse argumento, uma grave interferência em assuntos domésticos. Ademais, recupera um argumento de ordem jurídica, mobilizado por agentes do Itamaraty, que alude mais especificamente ao modus operandi da Justiça brasileira. Não obstante, nessa, que é a única nota editorial desse jornal a comentar diretamente o impasse do Brasil em aceitar ou não a jurisdição da Corte Interamericana de Direitos Humanos, sustenta-se que o país, através de seus decisores em matéria de política externa, deveria sim aceitar a jurisdição da Corte, e que os argumentos em contrário se conformavam apenas em uma "Má desculpa".

Desponta ainda como uma publicação relevante a coluna "Defesa do cidadão Nossos direitos fundamentais para o Brasil e o mundo". Assinada por Betch Cleinman em edição de 23 de maio de 1998, a publicação expõe para a opinião pública que o país ainda não havia se sujeitado à jurisdição da Corte Interamericana de Direitos Humanos, destacando ainda o principal efeito advindo de tal decisão, a saber, a inacessibilidade a um tribunal supranacional garantidor de direitos. Na coluna, afirma-se que:

Na esteira dessas declarações (tratados sobre direitos humanos, como o Pacto Internacional dos Direitos Civis e Políticos), surgiu a Convenção Americana sobre Direitos Humanos, realizada em San José da Costa Rica, em 
novembro de 1969. O Brasil só vai ratificá-la em setembro de 92.

Apesar da ratificação, o Governo brasileiro não reconheceu a jurisdição da Corte Interamericana de Direitos Humanos prevista desse documento, pois não aceitou a sua cláusula 62. Ela estipula que todo Estado Parte reconhece 'como obrigatória, de pleno direito e sem convenção especial a competência da Corte para conhecer de qualquer caso relativo à interpretação e aplicação das disposições dessa Convenção'.

Com essa decisão, não temos a possibilidade de acesso à jurisdição internacional para resolver situações de desrespeito aos direitos humanos, uma vez esgotadas as vias processuais brasileiras. Quem se sentir lesado em seus direitos constitucionais, não pode recorrer a esse tribunal internacional para buscar a reparação. (Cleinman, 1998)

A decisão brasileira de finalmente reconhecer a jurisdição da Corte Interamericana de Direitos Humanos foi publicada no jornal em uma pequena nota, inserida em uma notícia sobre o sequestro do empresário Abílio Diniz. A nota, presente na 2a edição do jornal, em 10 de dezembro de 1998, é integralmente transcrita abaixo:

\begin{abstract}
Ao participar ontem da cerimônia do cinquentenário da Declaração Universal dos Direitos Humanos, no Palácio Itamaraty, o presidente Fernando Henrique anunciou o reconhecimento pelo Brasil da jurisdição (poder para fazer cumprir leis) obrigatória da Corte Interamericana de Direitos Humanos. De acordo com o presidente, isso prova a determinação do Governo de dar aos cidadãos todas as possibilidades de obtenção de justiça e reparação pelos direitos humanos violados. (O Globo, 1998)
\end{abstract}

Reconhece-se que a divulgação de um fato tão relevante em matéria de política externa, com repercussões domésticas tão significativas, em uma pequena nota incluída em uma notícia sobre fato diverso pode ser um ilustrativo de que tal decisão não suscitou um debate público significativo. Aventa-se que a referida nota pode ser indicativa de um possível desinteresse da mídia e da opinião pública nesse acontecimento. Ademais, ela também pode sinalizar para o fato de que tal decisão se originou meramente de debates empreendidos em círculos políticos mais restritos, envolvendo tão somente atores governamentais.

Ressalta-se, por fim, uma última notícia significativa sobre a questão. Em publicação de 14 de maio de 1999, o jornal indica que, para a Organização NãoGovernamental Human Rights Watch, a decisão do Brasil em aceitar a jurisdição da Corte Interamericana de Direitos Humanos foi um dos avanços que aconteceram no país nos últimos anos (O Globo, 1999). A notícia, ao destacar como as ONGs de direitos humanos valorizaram a referida decisão, pode também indicar um ativismo anterior desses mesmos agentes no sentido de se pressionar os policy makers. Ainda que o 
jornal, em nenhuma notícia anterior, cite a pressão exercida por ONGs, entende-se que essa é uma possibilidade a ser considerada. Nesse sentido, apesar de a decisão do Brasil em se submeter à Corte Interamericana de Direitos Humanos não ter aparentemente suscitado um grande debate público, pode ao menos ter mobilizado grupos mais reduzidos, como os ativistas de direitos humanos e as ONGs. A possível interferência desses atores não-governamentais na agenda externa do país é, com efeito, uma manifestação possível apenas no contexto democrático que o país vivenciava. Mais uma vez, destaca-se a importância do regime político para a conformação das decisões tomadas em política externa.

Em comparação ao jornal O Globo, o periódico Jornal do Brasil publicou, no mesmo período, mais notícias, editoriais e colunas sobre o tópico em questão. Destaca-se como uma primeira publicação relevante um artigo publicado na edição do dia 22 de novembro de 1990 na seção "Opinião". Assinado por Antônio Augusto Cançado Trindade, então professor titular da Universidade de Brasília e membro do Conselho Diretor do Instituto Interamericano de Direitos Humanos, o artigo argumenta em favor da ratificação do país de importantes tratados internacionais. Ao fazê-lo, o autor mobiliza importantes argumentos que endossam a adesão generalizada a todas as tratativas internacionais de proteção aos direitos humanos. Assim inicia a coluna:

Há cerca de cinco anos, precisamente em 28 de novembro de 1985, foram encaminhadas ao Congresso Nacional as Mensagens Presidenciais 621 e 620, que submeteram à aprovação parlamentar, respectivamente, a Convenção Americana de Direitos Humanos de 1969 e os dois Pactos de Direitos Humanos das Nações Unidas (Pacto de Direitos Civis e Políticos e Pacto de Direitos Econômicos, Sociais e Culturais) de 1966, para posterior ratificação ou adesão pelo governo brasileiro. Hoje, decorrida meia década, aqueles três tratados humanitários continuam aguardando a aprovação o Congresso para que possam vir a ser ratificados pelo Executivo, como há tanto tempo se espera; Congresso e governo estão a dever às gerações presentes e futuras de brasileiros a sua aprovação e ratificação, respectivamente.

A adesão aos tratados humanitários é certamente condição sine qua non para um tratamento com seriedade, por parte dos estados, da proteção dos direitos humanos; é, além disto, passo decisivo no processo de consolidação da proteção dos direitos humanos nos planos nacional e internacional. Mas constitui uma relevante etapa, e não o final desse longo processo. Efetuada a adesão, ainda resta um longo caminho a percorrer: o aprimoramento e fortalecimento dos mecanismos de supervisão internacional requerem a aceitação pelos estados dos instrumentos e cláusulas facultativos dos tratados humanitários, a preverem o direito de petição individual e interestatal e a competência obrigatória dos órgãos internacionais de supervisão, que constituem elementos centrais e fundamentais da 
institucionalização da proteção internacional dos direitos humanos.

Assim, paralelamente ao aperfeiçoamento das instituições nacionais, se desejar o Brasil realmente projetar a imagem de um país garantidor dos direitos humanos e se desejar o Brasil verdadeiramente buscar a plenitude da proteção dos direitos humanos a nível nacional e internacional, sua esperada adesão à Convenção Americana e aos dois Pactos das Nações Unidas de Direitos Humanos há de efetuar-se de forma integral, isto é, sem quaisquer reservas ou declarações interpretativas, e há de englobar os instrumentos e cláusulas facultativos. Em outras palavras, a referida adesão do Brasil há de fazer-se acompanhar de outras providências a serem tomadas pelo Brasil no tocante àqueles três tratados humanitários, a incluírem a adesão ao Protocolo Facultativo ao Pacto de Direitos Civis e Políticos das Nações Unidas, que reconhece e regulamenta o direito de petição individual, e a declaração de reconhecimento da competência obrigatória da Corte Interamericana de Direitos Humanos, sob o Artigo 62 da Convenção Americana sobre Direitos Humanos. (Trindade, 1990).

Do trecho exposto, reconhece-se uma argumentação mais generalizada acerca da importância dos tratados de direitos humanos que culmina em uma defesa mais específica da submissão do país à jurisdição da Corte Interamericana de Direitos Humanos. Considera-se que a dita publicação pode ser um importante veículo a partir da qual setores da população brasileira, já no início da década de 1990, pudessem ter contato com o tema dos direitos humanos e com os argumentos em favor da adesão do Brasil aos regimes internacionais de proteção aos direitos humanos. O panorama apresentado por Cançado Trindade, acrescido dos argumentos que suscita, poderia representar uma possibilidade de sensibilização dos leitores desse periódico para a agenda dos direitos humanos e em defesa das ações externas resultantes da aceitação dessa agenda.

Notabilizam-se ainda os argumentos mobilizados por Cançado Trindade em defesa da aceitação da jurisdição da Corte Interamericana de Direitos Humanos. Apresentando o tribunal como uma instância complementar ao direito interno e explicitando a especificidade dos direitos humanos, os quais dependeriam de uma proteção que se sobrepujaria aos limites do Estado-Nacional, o autor busca desconstruir os argumentos ditos soberanistas. Assim argumenta Cançado Trindade:

A responsabilidade básica ou primária pela proteção dos direitos humanos, inclusive como o reconhecem os próprios tratados humanitários, recai certamente nos órgãos e instrumentos do ordenamento jurídico interno, mas não se esgota neste, não se esgota na ação do Estado: é justamente quando falham as instituições nacionais que os mecanismos internacionais de proteção, de caráter subsidiário, são e devem ser acionados na defesa da pessoa humana. (...) A adesão aos tratados humanitários constitui garantia 
adicional, já não só no plano nacional, como também internacional (ambos em interação), de eficaz proteção contra a violação dos direitos humanos. (...) O domínio da proteção internacional dos direitos humanos reveste-se hoje de especificidade própria, não se prestando a analogia com os mecanismos clássicos de solução pacífica de controvérsias internacionais no plano do contencioso puramente interestatal discricionário. Conta com mecanismos próprios de supervisão, inspirados por considerações de ordre public, a guiarem suas interpretações e aplicação, em prol da salvaguarda dos direitos da pessoa humana. (Trindade, 1990).

A argumentação em favor da especificidade dos direitos humanos, que justificaria a possibilidade de arbítrio internacional em questões referentes a essa matéria, ressurge em publicação datada de 4 de maio de 1997. Em entrevista ao jornal, o professor Fábio Konder Comparato, ao comentar a decisão do Brasil de não reconhecer a jurisdição da Corte Interamericana de Direitos Humanos, afirma:

O governo cedeu à pressão do Itamaraty e se recusou a reconhecer a jurisdição obrigatória da Corte Interamericana de Direitos Humanos. O que ocorreu é que o governo brasileiro, conforme reconheceu o próprio representante do Itamarati no Conselho de Defesa dos Direitos da Pessoa Humana no Ministério da Justiça, não tem como gerir as reclamações internacionais de violação dos direitos humanos contra oBrasil, que já são mais de uma centena. No estado atual do direito internacional, proteção dos direitos humanos deixou de ser estatal ou nacional. Ela hoje é universal e supra-estatal. Estamos na contramão da história. (Marques, 1997).

Para além de corroborar a visão anteriormente destacada de Cançado Trindade, Comparato sinaliza para uma resistência dentro do Ministério das Relações Exteriores quanto à aceitação da jurisdição da Corte. Dentre as notícias encontradas, esta é a primeira a apresentar a possibilidade de que uma tensão inter-governamental, capitaneada por uma das burocracias do governo brasileiro, o Itamaraty, tivesse retardado a decisão brasileira de aderir à Corte Interamericana de Direitos Humanos. Desponta, com efeito, a possibilidade de agentes do Ministério das Relações Exteriores terem pressionado o governo no sentido de não reconhecer a jurisdição de dita corte. A entrevista publicada evidencia ainda como uma publicação midiática pode ajudar a descortinar um processo decisório em matéria de política externa pretérito.

A Corte Interamericana de Direitos Humanos é didaticamente descrita aos leitores em uma matéria sobre o Tribunal Penal Internacional, publicada em edição de 26 de julho de 1998, na seção "Internacional". Em uma subseção intitulada "As cortes nacionais já existentes", a Corte Interamericana não é somente descrita, mas se destaca o fato de que o Brasil até então não havia se submetido à sua jurisdição: 
Único tribunal supranacional em funcionamento nas Américas, com sede na Costa Rica. Foi criado em 1979, mas o Brasil, os EUA e o México não reconhecem sua jurisdição, embora um dos seus sete juízes seja brasileiro Antônio Augusto Cançado Trindade -, que deve ser o próximo presidente da instituição. A Organização dos Estados Americanos (OEA) também possui uma Comissão Interamericana de Direitos Humanos, que supervisiona os países-membros e pode remeter processos à Corte da Costa Rica. (Ninio, 1998).

Ainda em 1998, em publicação de 8 de setembro, o jornal informa que um importante passo fora tomado em direção à aceitação da jurisdição da Corte Interamericana de Direitos Humanos. Através da notícia "FH cobra mais rapidez da Justiça", informa-se que "O presidente também mandou ao Congresso um projeto de lei que reconhece a competência da Corte Interamericana de Direitos Humanos para julgar abusos que venham a ser cometidos" (Lana; Fagundes, 1998).

Finalmente, a decisão brasileira de aceitar a jurisdição da Corte Interamericana de Direitos Humanos resultou em um extenso artigo publicado na seção internacional da edição de 10 de dezembro de 1998. Diferentemente de O Globo, identifica-se, portanto, que o Jornal do Brasil deu uma importância maior a este tópico. Em coluna assinada por Renato Fagundes, lê-se que:

No ano em que a Declaração Universal dos Direitos do Homem completa 50 anos, o Brasil tomou uma iniciativa a que resistia desde 1992: passou a reconhecer os julgamentos da Corte Interamericana de Direitos Humanos para atos considerados lesivos às garantias previstas na Declaração. A cláusula aceitando o julgamento pela corte foi recusada pelo Brasil quando da assinatura da Convenção Interamericana de Direitos Humanos, há seis anos. Com isso, o país se comprometeu a aceitar as garantias impostas pelo documento, mas não se submeteria às decisões do tribunal criado para fiscalizar a convenção.

O reconhecimento do poder da Corte foi resultado de uma iniciativa do secretário nacional de Direitos Humanos, José Gregori, que será premiado hoje pela ONU.

Até o reconhecimento da Corte Interamericana, as violações de direitos humanos praticadas no Brasil eram sujeitas apenas ao julgamento formal da Comissão Interamericana de Direitos Humanos. A única pena era o constrangimento da divulgação do crime e da informação de que o governo fora inoperante. A nova posição brasileira de reconhecer a jurisprudência internacional em casos de violação dos direitos humanos, como os crimes de genocídio, também foi expressa no apoio, em julho, à criação do Tribunal Penal Internacional. (Fagundes, 1998).

A publicação transcrita reveste-se de fundamental importância, pois, além de apontar uma possível figura protagônica que teria pressionado o governo a reverter a decisão tomada em 1992 e aderir à jurisdição da Corte - o secretário nacional de 
direitos humanos, José Gregori -, ela igualmente situa dita decisão dentro do macroprocesso de adesão do Brasil aos regimes internacionais de direitos humanos, macroprocesso esse que teria finalmente resultado na refutação do argumento soberanista quando o Brasil aceitou a jurisdição do Tribunal Penal Internacional. Sob essa ótica, a submissão aos auspícios da Corte Interamericana de Direitos Humanos seria um resultado de uma revisão do princípio da soberania em face do avanço da agenda dos direitos humanos em âmbito internacional. A soberania irrestrita teria sido finalmente superada com o endosso do Brasil à criação do Tribunal Penal Internacional (TPI). Assim sendo, a reversão da decisão de 1992 no tocante à Corte Interamericana de Direitos Humanos, aliada ao apoio à criação do TPI, seriam evidências da ressignificação do princípio de soberania estatal pelos policy makers brasileiros.

A decisão de 9 de dezembro de 1998 é citada e celebrada em entrevista com Antônio Augusto Cançado Trindade, nesse momento vice-presidente da Corte Interamericana de Direitos Humanos, publicada em 20 de dezembro de 1998. Nessa entrevista, Trindade recupera os argumentos que já havia anunciado na coluna de 1990, confirmando serem os direitos humanos uma agenda dotada de especificidades que demandam o atendimento suplementar por parte de tribunais internacionais:

\footnotetext{
A aceitação pelo Brasil da competência da Corte Interamericana representa o ponto culminante de um processo iniciado com a decisão de 1985 de adesão do Brasil à Convenção Americana sobre Direitos Humanos, concretizada em 1992, e de ratificação dos dois Pactos de Direitos Humanos das Nações Unidas, efetuada em 1990. Pela nova iniciativa, o Brasil reconhece, enfim, que não era razoável aceitar apenas as normas substantivas dos tratados de direitos humanos, fazendo abstração dos mecanismos processuais para reivindicação e salvaguarda desses direitos.

Essa aceitação constitui uma garantia adicional, pelo Brasil, a todas as pessoas sujeitas à sua jurisdição, da proteção de seus direitos (como consagrados na Convenção Americana), quando as instâncias nacionais não se mostrarem capazes de garanti-los. Em face de insuficiências e carências do direito interno, muitos casos de direitos humanos que as instâncias nacionais não conseguiram resolver só têm encontrado solução graças às instâncias internacionais protetoras. (Carneiro, 1998).
}

A decisão é também celebrada, segundo notícia publicada pelo jornal, pelo então chanceler Luiz Felipe Lampreia. Em matéria intitulada "Brasil condena predomínio da força", publicada na edição de 10 de maio de 1999, lê-se que "Lampreia citou, entre medidas que resgatam 'hipotecas' do passado, o reconhecimento da jurisdição obrigatória da Corte Interamericana de Direitos Humanos, ano passado" (Jornal do 
Brasil, 1999). Essa notícia aponta uma outra possibilidade durante o processo decisório, qual seja, a argumentação em favor da aceitação da jurisdição da Corte Interamericana pelo então chanceler, via de regra importante ator partícipe do processo decisório em política externa.

Destacam-se, por fim, publicações que, mais particularmente, comentam a decisão brasileira de submeter o país à jurisdição da Corte à luz do argumento da soberania nacional. Primeiramente, em coluna intitulada "Reflexos múltiplos no Direito", assinada por Nelson Franco Jobim, com redação, e publicada na seção Internacional da edição de 2 de maio de 1999, recupera-se a fala de uma embaixadora brasileira que afirma que, em esferas como os direitos humanos, o conceito de soberania precisa ser repensado. Assim se apresenta a coluna:

No Brasil, os diplomatas vêm discutindo há algum tempo a questão da superposição entre os princípios da soberania dos Estados, consagrado na Carta da ONU, e da defesa dos direitos humanos. Em que momento as violações desses direitos passam a ser consideradas uma ameaça à paz e à segurança internacionais, a ponto de justificar uma intervenção?

'Em certas áreas como direitos humanos não se pode falar de um conceito absoluto de soberania', diz a embaixadora Celina do Valle, chefe do Departamento de Organismos Internacionais do Itamarati. Por outro lado, a defesa dos direitos humanos não pode, na sua visão, partir de ações unilaterais. 'É preciso ter uma instância legitimadora e reforçar o multilateralismo, que é a nossa tradição', afirma ela.

Segundo a embaixadora, esse tema ganhou nos últimos anos uma atenção especial do Itamarati, que em 1995 criou o Departamento de Direitos Humanos e Temas Sociais (saúde, mulher, racismo). O atual chefe deste departamento, ministro Marco Antônio Brandão, lembra que ano passado o Brasil aceitou a jurisprudência da Corte Interamericana de Direitos Humanos, 'na primeira vez em que se reconheceu um tribunal externo para julgar casos brasileiros'. (Jobim, 1999).

Essa notícia notabiliza-se não apenas por reforçar o argumento de que os direitos humanos se sobreporiam à visão tradicional de soberania, ensejando ações externas diferenciadas, como também por manifestar, ainda que de forma embrionária, como o Itamaraty lidou com esse tema ao longo da década de 1990. Através da notícia, vislumbra-se a possibilidade de o ministério ter experimentado diferentes fases ao longo da década de 1990, acerca da adesão internacional aos temas de direitos humanos: em um primeiro momento, o Itamaraty teria se pautado pela defesa irrestrita do princípio da soberania nacional; posteriormente, teria reconhecido a importância crescente dos direitos humanos, reorganizando-se internamente e criando um 
departamento específico para lidar com essas questões; finalmente, o ministério teria concluído que os direitos humanos afiguravam-se em excepcionalidades e justificavam uma revisão do conceito de soberania nacional. Nesse momento, o ministério teria aquiescido com a decisão de submeter o país à jurisdição de um tribunal internacional de defesa de direitos humanos.

O argumento soberanista é novamente refutado em nova entrevista com Cançado Trindade, publicada em 20 de setembro de 1999. Durante a notícia "Brasileiro preside corte", publicada na edição de 20 de setembro de 1999, registram-se falas de Cançado Trindade que endossam a excepcionalidade dos direitos humanos e recuperam argumentos em favor da aceitação da jurisdição da Corte. Tais falas são reproduzidas a seguir:

\footnotetext{
Ano passado, o Brasil aceitou a jurisdição da Corte, que julga casos encaminhados pela Comissão Interamericana de Direitos Humanos. Em entrevista ao JB em novembro de 1998, a propósito da detenção em Londres do ex-ditador chileno Augusto Pinochet, o juiz Cançado Trindade não quis comentar diretamente o caso, mas afirmou que 'não pode haver anistia para a tortura'. Disse ainda que no mundo 'não há espaço para a invocação de soberania' em casos de violações graves de direitos humanos. Par ao juiz, os cidadãos da América Latina devem no futuro ter o direito de recorrer diretamente à Corte, como acontece com o Tribunal Europeu de Direitos Humanos. (Jornal do Brasil, 1999).
}

Ao corroborar a percepção de que as graves violações de direitos humanos não podem escudar-se no argumento da preservação da soberania nacional, Trindade transmite, à opinião pública brasileira, o imperativo da desconstrução da soberania irrestrita em favor de uma projeção internacional mais humana por parte do Brasil, que protegeria mais enfaticamente os direitos humanos, inclusive de sua própria população. Essa nova projeção internacional pretendida por Trindade culminaria, finalmente, no direito de petição individual dos brasileiros a um tribunal internacional de direitos humanos, a exemplo do que já acontecia na Europa. Trata-se, mais uma vez mais, de uma publicação que argumenta em favor da aceitação do Brasil da jurisdição da Corte Interamericana de Direitos Humanos.

\section{CONSIDERAÇÕES FINAIS}

Ao longo do artigo, intentou-se obter um panorama generalizado do processo decisório que culminou na aceitação, por parte do Brasil, de um tribunal internacional 
de direitos humanos, a Corte Interamericana de Direitos Humanos. Com o apoio de teóricos inseridos no âmbito da APE, revelou-se a importância de adentrar as instâncias decisórias internas a fim de obter uma explicação mais completa sobre as razões e circunstâncias que levam um país a adotar determinados comportamentos internos. Tendo por base esse norte teórico, buscou-se evidenciar o processo decisório em política externa que antecedeu a tomada de decisão do Brasil de se submeter à jurisdição da Corte Interamericana de Direitos Humanos. Esse esforço foi operacionalizado a partir da investigação de notícias publicadas nos periódicos O Globo e Jornal do Brasil.

As publicações coletadas não parecem sugerir, a priori, uma politização da política externa no caso em questão. Contrariamente, elas sugerem um baixo interesse da população brasileira nesse tópico. Corrobora para essa leitura o reduzido número de notícias que tratam da adesão brasileira à Corte Interamericana de Direitos Humanos, uma decisão que já é por si grandiosa, haja visto que, pela primeira vez, o Brasil havia aceitado se submeter a um tribunal internacional, autorizando que seus nacionais tivessem acesso a uma proteção adicional. Apesar de aparentemente significativa, a adesão do Brasil à Corte não parece ter suscitado grande interesse por parte da população brasileira. Também convergiria para esse entendimento o fato de que, nos jornais analisados, não se encontrou um único comentário de leitores acerca da decisão brasileira, ou mesmo posicionamentos em contrário à adesão do Brasil à Corte Interamericana de Direitos Humanos, que demonstrariam haver um debate em curso no país. Ao que parece, a decisão do Brasil de se submeter à Corte aconteceu ao largo da opinião pública brasileira, devendo suas motivações serem perseguidas no âmbito do próprio círculo governamental e nas mudanças operacionalizadas no cenário internacional.

Não obstante, reconhece-se que o acesso limitado às fontes que subsidiaram as análises contidas no presente trabalho não esgota possibilidades alternativas. Com efeito, é possível que o processo decisório em política externa que culminou na sujeição do Brasil à Corte Interamericana de Direitos Humanos tenha sido menos insular do que sugere a mera interpretação das publicações de O Globo e do Jornal do Brasil. Diversos 
autores apontam para uma comparativa pluralização dos entes governamentais influentes sobre política externa nos anos 1990. Segundo esclarecem Carlos Milani e Letícia Pinheiro:

No Brasil, a década de 1980 testemunhou um movimento de êxodo de diplomatas para outras agências governamentais, ao passo que a década de 1990 foi palco de um movimento distinto, embora não antagônico ao anterior: a incorporação crescente de temas de política externa por outras agências do governo. A nosso ver, embora esse segundo movimento tenha ocorrido principalmente em função da mudança na natureza das questões domésticas que, com os efeitos da globalização sobre a política, a economia e a cultura, foram se tornando, dia após dia, mais próximos dos temas internacionais, a presença de pessoal formado no Instituto Rio Branco nas outras agências em muito colaborou para que se atentasse para a potencialidade, as articulações e tensões desses temas "domésticos" com as agendas da PEB. Como resultado, passou-se a questionar o que antes parecia ser senso comum, ou seja, a relativa autonomia e o insulamento burocrático do Itamaraty no processo de formulação e condução da política externa. (2013, pp. 17-18)

Do parágrafo supracitado, subentende-se que emerge, nesse período, a possibilidade de influência de atores não tradicionalmente participantes do processo decisório em política externa. Embora a análise de Milani; Pinheiro (2013) atente tãosomente para a pluralização de atores governamentais, subentende-se que a possibilidade de interveniência de atores não-governamentais está também contemplada nesse fenômeno de perda relativa da hegemonia do Itamaraty. Na esteira desse processo, organizações como grupos protetores de direitos humanos poderiam ter emergido como importantes vozes a defender a promoção de determinadas agendas em política externa. Com efeito, a democratização política certamente teve efeitos consideráveis sobre o processo decisório em política externa.

Por ora, reconhece-se que a decisão brasileira de aceitar a jurisdição da Corte Interamericana de Direitos Humanos combina elementos de ordem interna com imposições sistêmicas. Em termos de política interna, destaca-se a ascensão do governo de Fernando Henrique Cardoso e a inflexão de política externa promovida nesse período, a qual ressignificou o conceito de autonomia e passou a considerar que a melhor forma de obter autonomia no cenário internacional seria por intermédio da adesão aos principais regimes internacionais, tal como manifesto no princípio do multilateralismo normativo focalizado em Cervo (2008). Nesse sentido, a submissão à Corte Interamericana de Direitos Humanos, a exemplo da adesão ao Tratado de Não- 
Proliferação Nuclear (TNP) teria se orientado segundo essa nova lógica de inserção internacional. Ademais, aventa-se a hipótese partilhada em Hill Jr. (2018), segundo a qual a decisão de submeter um país à jurisdição de um tribunal internacional de direitos humanos deve ser pensada como uma sinalização à comunidade internacional de que a defesa dos referidos direitos é um compromisso de Estado que não admitirá retrocessos. Assim sendo, os governos, ao optarem por mecanismos de supervisão e controle internacional, criariam medidas de contenção que impediriam que governos futuros promovessem recuos na defesa dos direitos humanos. Sobretudo em países que passaram por experiências autoritárias recentes, a decisão de aderir à jurisdição de um tribunal internacional desponta como um gesto direcionado à comunidade internacional para enfatizar que retrocessos democráticos não serão tolerados, e que a defesa dos direitos humanos transcende a mera disposição de um único governo, sendo, em contrário, uma política de Estado.

Em termos sistêmicos, destacam-se a emergência da agenda dos direitos humanos e as pressões cada vez mais acentuadas de países centrais como os Estados Unidos no sentido de se promover essa agenda. Ademais, a recusa brasileira colocava o país em uma posição incômoda no subcontinente sul-americano, visto que o Brasil era um dos únicos da região a não ter aceitado a jurisdição da Corte em meados/finais dos anos 1990. Decerto, os principais formuladores de política externa no país possivelmente concluíram que tal isolamento já não era mais de interesse do país, e vislumbraram, na aceitação da jurisdição da Corte Interamericana de Direitos Humanos, uma decisão que eliminaria, por definitivo, uma possível suspeição quanto às práticas brasileiras em se tratando da proteção dos direitos humanos.

São infinitas as linhas de investigação possível. O presente trabalho apenas apresentou algumas delas, buscando salientar o vínculo entre política externa, democracia e direitos humanos, além da crescente ressignificação da soberania diante da emergência dos direitos humanos. Acredita-se que os direitos humanos, enquanto agenda provedora de direitos e promotora de benefícios individuais e coletivos, dependem da democracia para se afirmar. Compromissos assumidos externamente sem a chancela da população interna em um tema tão sensível quanto os direitos humanos 
estão destinados à inviabilidade. Os direitos humanos envolvem uma nova concepção ética, a assunção de um compromisso humanitário que transcende a chancela do Estado. Se admitidos em um contexto de política externa insular desconectada dos anseios populares, os direitos humanos certamente terão dificuldades em se afirmar socialmente no Brasil. E por isso a distância tão ampla entre os compromissos internacionalmente assumidos e sua aplicabilidade no país. Considera-se como um importante embaraço ao pleno desenvolvimento dos direitos humanos no Brasil a forma como eles foram operacionalizados por uma burocracia autônoma em um processo não dialógico. O trabalho dá início à investigação dessa hipótese. Se a resposta à pergunta norteadora confirmar que o Brasil meramente aceitou se sujeitar à Corte Interamericana de Direitos Humanos por entender que tal decisão ajudaria o país a alcançar seus objetivos internacionalmente, e se for posteriormente confirmado que a decisão em questão não se referendou em uma discussão aberta à pluralidade de vozes, ter-se-á um indicador de que a forma insular pela qual o Brasil lidou com a temática dos direitos humanos no cenário internacional é um dos principais obstáculos à promoção dessa agenda na atualidade, sendo ainda responsável pela distância tão ampla entre a realidade interna e a realidade firmada externamente. Nessa linha de investigação seguirão projetos futuros.

\section{REFERÊNCIAS BIBLIOGRÁFICAS}

Alden, C.; Aran, A. (2012). Foreign Policy Analysis. New Approaches. New York, Routledge, p. 1-13.

Carneiro, L. (1998). "Não há anistia para a tortura'”. Jornal do Brasil, 20 dezembro, Internacional, p. 34.

Cervo, A. (2008). Inserção Internacional - formação dos conceitos brasileiros. São Paulo, Ed. Saraiva.

Cleinman, B. (1998). "Nossos direitos fundamentais para o Brasil e o mundo". O Globo, 23 maio, Rio, p. 16.

Comparato, F. (2015). A Afirmação Histórica dos Direitos Humanos. 7ạ ed. São Paulo: Saraiva.

Fonseca Jr., G. (1998). A Legitimidade e outras questões internacionais. Poder e ética entre as nações. São Paulo, Paz e Terra. 
Fagundes, R. (1998) "No Brasil, avanços na legislação". Jornal do Brasil, 10 dezembro, Internacional, p. 23.

Guerra e Silva, R. (2018). Argentina y Brasil frente al Sistema Interamericano de Derechos Humanos: el rol de las organizaciones no gubernamentales en el cambio político doméstico. Dissertação de mestrado. Universidade Torcuato di Tella.

Hill, C. (2003). The Changing Politics of Foreign Policy. Londres, Palgrave Macmillan, cap. 2.

Hill Jr, D. (2018). Why Governments Cede Sovereignty: Evidence From Regional Human Rights Courts. Foreign Policy Analysis. Disponível em: <doi:10.1093/fpa/orw031>.

Hudson, V.; Vore, C. (1995). "Foreign Policy Analysis Yesterday, Today and Tomorrow". Mershon International Studies Review, 39(2), Oct./1995, p. 209-238.

(2012). "The history of foreign policy analysis", in: Smith, S.; Hadfield, A.; Dunne, T. (eds.). Foreign Policy. Theories, actors, cases. Oxford, Oxford University Press, p.13-34.

Jobim, N. (1999) "Reflexos múltiplos no Direito". Jornal do Brasil, 2 maio, Internacional, p. 32.

Jornal do Brasil. (1999) "Brasil condena predomínio da força". Jornal do Brasil, 10 maio, Internacional, p. 11.

6. . (1999). "Brasil preside Corte". Jornal do Brasil, 20 setembro, Internacional, p.

Lana, F.; Fagundes, R. (1998). "FH cobra mais rapidez da Justiça". Jornal do Brasil, 09 setembro, Brasil, p. 7.

Lima, M. (2000). "Instituições Democráticas e Política Exterior". Contexto Internacional, 22(2). Rio de Janeiro, IRI/PUC-RJ, jul-dez. p. 265-303.

Marques, F. (1997). "Entrevista/Fábio Konder Comparato". Jornal do Brasil, 4 maio, p. 12.

Milani, C.; Pinheiro, L. (2013). "Política Externa Brasileira: os desafios de sua caracterização como política pública". Contexto Internacional, 35(1), jan-jul, p. 11-41.

Miranda, M.; Cunha, J. R. (2010). Poder Judiciário brasileiro e a proteção dos direitos humanos: Aplicabilidade e incorporação das decisões da Corte Interamericana de Direitos Humanos. FGV Editora, Rio de Janeiro, 126p.

Ninio, M. "Um tribunal acima de 120 países". Jornal do Brasil, 26 julho, Internacional, p. 18.

O Globo. (1995). "Má desculpa”. O Globo, 28 outubro, O País, p. 5. 
(1998). "Chile cobra solução para sequestradores". O Globo, 10 dezembro, Matutina, O País, p. 11.

(1999). "ONG critica lentidão do Programa de Direitos Humanos". O Globo, 14 maio 1999, Matutina, O País, p. 5.

Ramos, G. (2018). "A evolução do Direito Internacional dos Direitos Humanos (DIDH): a humanização do direito internacional e os debates acerca da responsabilidade social das corporações empresariais na provisão de direitos humanos", in: Instituto Global Attitude. Cadernos de Diplomacia Pública: Melhores artigos de 2017. São Paulo. Disponível em: <http://diplomaciacivil.org.br/publicacoes/publicacoes-2017>. [Acesso em: 08 de jul. 2019].

Rispman, N.; Taliaferro, J.; Lobell, S. (2016). Neoclassical Realist Theory of International Politics. Oxford: Oxford University Press.

Sarmento, D. (2016). Dignidade da pessoa humana: conteúdo, trajetórias e metodologia. 1a edição. Belo Horizonte: Fórum.

Sen, A. (2010). Desenvolvimento como liberdade. São Paulo: Companhia das Letras.

Trindade, A. (1990). "O Brasil e os tratados de direitos humanos". Jornal do Brasil, 22 novembro, 1을 caderno, p. 11.

Velasco Jr, P. (2019). "Política Externa, democracia e sociedade no Brasil: equação de difícil solução", in: Ávila, C. D. F.; Xavier, L. de O.; Fonseca, V. A qualidade da democracia no Brasil: questões teóricas e metodológicas da pesquisa. Curitiba: Editora CRV, p. 473504. 